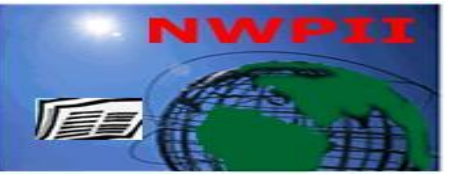

American Journal of Biomedical Sciences

ISSN: 1937-9080

nwpii.com/ajbms

\title{
Nox2ds-Tat, A Peptide Inhibitor of NADPH Oxidase, Exerts Cardioprotective Effects by Attenuating Reactive Oxygen Species During Ischemia/Reperfusion Injury
}

\author{
Qian Chen, Issachar Devine, Sydney Walker, Hung Pham, Regina Ondrasik, Harsh Patel, \\ William Chau, C. Woodworth Parker, Kyle D. Bartol, Shayan Riahi, Ashita Mittal, Robert Barsotti, \\ Lindon Young*
}

Department of Bio-Medical Sciences, Philadelphia College of Osteopathic Medicine, 4170 City Avenue, Philadelphia, USA.

Corresponding Author

Lindon Young, Ph.D.

Department of Bio-Medical Sciences

Philadelphia College of Osteopathic Medicine (PCOM)

4170 City Avenue

Philadelphia, PA 19131

USA

Tel: 215.871 .6832

Fax: 215.871.6869

Email: Lindonyo@PCOM.edu

Received: 15 July 2016; | Revised: 14 August 2016; $\mid$ Accepted: 07 September 2016

\begin{abstract}
Myocardial infarction is a form of ischemia/reperfusion (I/R) injury that causes cardiac contractile dysfunction and cell death. I/R injury is mediated, in part, by decreased endothelial-derived nitric oxide (NO) bioavailability and increased reactive oxygen species (ROS) resulting in cell death. Cytokines released from I/R tissue activate G-protein coupled receptors that in turn stimulate NADPH oxidase to produce ROS. Thus, administration of a NADPH oxidase peptide inhibitor, Nox2ds-tat (formerly known as gp91ds-tat), may be a rational approach to attenuate I/R injury. Nox2ds-tat dose-dependently inhibited $(10 \mu \mathrm{M}-80 \mu \mathrm{M} ; \mathrm{n}=5)$ phorbol 12-myristate13-acetate $(\mathrm{n}=21)$ induced polymorphonuclear leukocyte superoxide production up to $37 \pm 7 \%$ (p<0.05; Fig. 3). Similarly, Nox2ds-tat dose-dependently attenuated I/R induced cardiac contractile dysfunction as evidenced by improved post-reperfused left ventricular developed pressure (LVDP) which recovered up to $77 \pm 7 \%(5 \mu \mathrm{M}-80 \mu \mathrm{M} ; \mathrm{p}<0.05 ; \mathrm{n}=6-7)$ of initial values (pre-ischemic values) at $45 \mathrm{~min}$ post-reperfusion when compared to control I/R hearts $(n=14)$ that only recovered to $46 \pm 6 \%$ from initial values for LVDP in isolated perfused rat hearts subjected to global I(30 min)/R(45 min) (Table 1). I/R control hearts exhibited an infarct size of $46 \pm 2.1 \%$, whereas $\mathrm{I} / \mathrm{R}+$ Nox $2 \mathrm{ds}$-tat hearts exhibited infarct sizes of $30 \pm 4 \%(5 \mu \mathrm{M}), 15 \pm 1.4 \%(10 \mu \mathrm{M}), 23 \pm 2.0 \%(40 \mu \mathrm{M})$, and $19 \pm 1.6 \%(80 \mu \mathrm{M})(\mathrm{p}<0.01 \mathrm{vs}$. control I/R hearts; Figure 4, Panel A-B). Regarding in vivo assessments, Nox2ds-tat (4.1 mg/kg, IV) significantly reduced blood $\mathrm{H}_{2} \mathrm{O}_{2}(1.4 \mu \mathrm{M})$ and increased endothelial-derived blood $\mathrm{NO}(127 \mathrm{nM})$ at 45 min reperfusion
\end{abstract}


compared to saline controls $(\mathrm{p}<0.01)$ in rat hindlimb I(30 min)/R (45 min). Moreover, Nox 2ds-tat $(20 \mu \mathrm{M})$ dose-dependently and significantly attenuated $\mathrm{N}^{\mathrm{G}}$-L-arginine methyl ester (L-NAME) induced leukocyte endothelial interactions up to five-fold compared to L-NAME controls $(p<0.01)$. These results were confirmed by changes seen in the histology of rat mesenteric venules (Figure 7, Panel A-B). The results suggest that Nox2ds-tat attenuates I/R-induced cardiac contractile dysfunction and infarct size by inhibiting ROS release from NADPH oxidase.

Keywords: NADPH oxidase, Nox2ds-tat, myocardial I/R, hindlimb I/R, nitric oxide, hydrogen peroxide, leukocyte superoxide release, leukocyte endothelial interactions.

\section{Introduction}

Myocardial infarction (MI) is the leading cause of death in the United States and is characterized by prolonged blockage of coronary blood flow to heart tissue, also known as ischemia. Reperfusion of blood to an ischemic area is necessary to reduce the initial damage caused by the ischemia; however, the process of reperfusion itself also initiates additional injury, which may contribute up to $50 \%$ of the final infarct size $[1,2]$. Oxidative stress at reperfusion is a key component of ischemia/reperfusion (I/R) injury characterized by the overproduction of oxygen-derived free radicals that can directly damage cells. These reactive oxygen species (ROS) also diminish the bioavailability of endothelial-derived nitric oxide (NO), resulting in vasoconstriction and inflammation. Leukocytes are then recruited to this area of inflammation, generating a "respiratory burst" of superoxide (SO) through activation of phagocytic Nox2 and ultimately exaggerating the final infarct size [3]. Attenuating these sources of oxidative stress can limit reperfusion-induced tissue death. However, the disappointing results from non-specific antioxidant agents in clinical trials suggest that it is critical to target the sources of oxidative stress during reperfusion rather than promote the use of general anti-oxidants to attenuate injury after reperfusion [2].

Nox2 is the principle isoform of NADPH oxidase present in leukocytes and cardiovascular tissue [4]. The inflammatory process induced by initial tissue injury up-regulates leukocyte migration and expression of adhesion molecules within the area of injury. This augmentation of leukocyte-endothelial interactions further exacerbates the oxidative stress at reperfusion, leading to a decrease in NO blood concentrations. A deleterious cycle of oxidative stress and I/R injury is hereby perpetuated, wherein inflammation promotes leukocyte-endothelial interactions and ROS production, which lead to NO quenching, which in turn causes increased inflammation and leukocyte-endothelial interactions [3]. The deleterious cycle of SO production and NO depletion can be prevented by identifying the source of oxidative stress and proactively inhibiting it.

There are four primary enzymatic sources that promote oxidative stress during reperfusion: NADPH oxidases, uncoupling of the mitochondrial electron transport chain, uncoupled endothelial NO synthase (eNOS), and xanthine oxidase activation. NADPH oxidases are a unique family of oxidases capable of exacerbating the other three sources of ROS and reperfusion injury (Figure 1) [4]. First, the assembly of cytosolic subunits (i.e., Rac, p67 $7^{\text {hox }}$, p4 $7^{\text {phox }}$, and p40 ${ }^{\text {phox }}$ ) with membrane subunits (i.e., p22 phox and gp91 ${ }^{\text {phox }}$ ) leads to the inherent production of $\mathrm{SO} /$ hydrogen peroxide $\left(\mathrm{H}_{2} \mathrm{O}_{2}\right)$ upon NADPH oxidase activation. Next, mitochondrial ATPdependent potassium channels and/or mitochondrial permeability transition pores are augmented by the release of $\mathrm{SO} / \mathrm{H}_{2} \mathrm{O}_{2}$ from activated NADPH oxidases (e.g., Nox2), resulting in mitochondrial matrix alkalization, electron transport chain uncoupling, and additional SO [5]. Additionally, NADPH oxidase derived $\mathrm{SO} / \mathrm{H}_{2} \mathrm{O}_{2}$ will cause eNOS uncoupling and promote the formation of xanthine oxidase via the oxidation of $\mathrm{BH}_{4}$ and xanthine dehydrogenase, respectively [6, 7]. Lastly, NADPH oxidase serves as a common signaling molecule that induces the release of inflammatory cytokines (e.g., TNF- $\alpha$ ) during the first 15 
minutes of reperfusion, augmenting inflammation associated injury [5-9]. It is evident that NADPH oxidase is a significant source of oxidative stress during reperfusion, both directly by producing ROS and indirectly by propagating mediators of I/R injury.

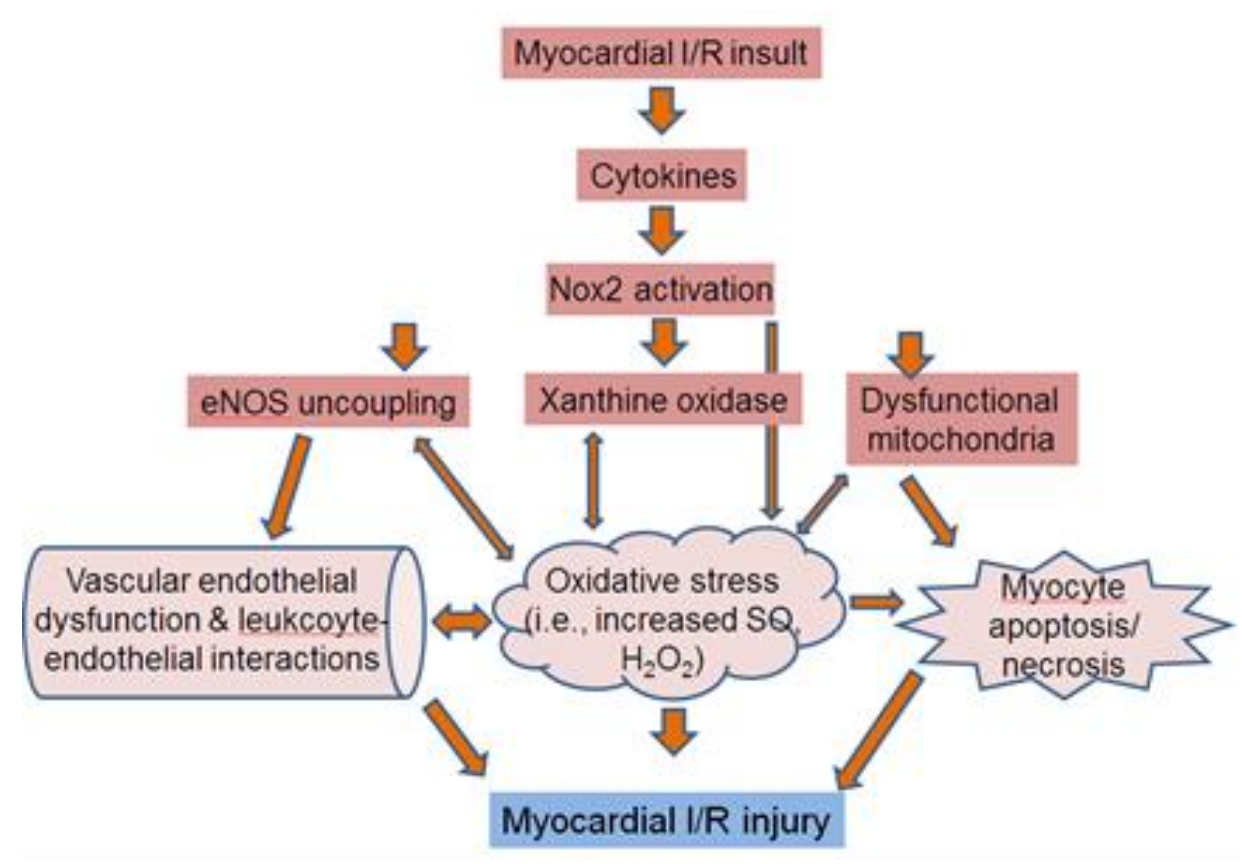

Figure 1. I/R insult initially leads to cytokine mediated receptor stimulation, followed by the activation of Nox2, which in turn produces SO. The SO released from Nox2 induces additional ROS release from xanthine oxidase, eNOS uncoupling, and dysfunctional mitochondria. Collectively, these sources of oxidative stress overproduce $\mathrm{SO} / \mathrm{H}_{2} \mathrm{O}_{2}$ species, and diminish the bioavailability of blood NO. This cyclical process of oxidative injury can promote further mitochondrial dysfunction, additional eNOS uncoupling, and stimulate xanthine oxidase. The aggregate response to this oxidative stress at reperfusion is endothelial dysfunction, leukocyte recruitment, cardiomyocyte death, and increased ROS production, all which lead to additional myocardial I/R injury.

The NADPH oxidase family contains seven members, among which Nox 2 has been suggested as an important isoform during myocardial $\mathrm{I} / \mathrm{R}$ [10]. First, Nox2 is a ubiquitous enzyme within several areas of the cardiovascular system, such as endothelial cells, adventitial fibroblasts, myocytes, and platelets, and is the primary source of SO production in Polymorphonuclear Leukocytes (PMNs). Secondly, Nox2 is located on the cell membranes and subcellular organelles of the aforementioned cells, such as the endoplasmic reticulum or nuclear membrane. The distribution of Nox2 allows it to affect mitochondria and eNOS coupling in multiple areas of the cell [11]. Third, Nox2 subunits can be up-regulated by $\mathrm{I} / \mathrm{R}$ related mediators such as inflammatory cytokines $[12,13]$. Fourth, Nox2 can sense the disturbance of blood flow during periods of ischemia (i.e., oscillatory and eddy current) and in response initiates vascular inflammation, which can exacerbate the initial ischemic event [14]. Lastly, Nox2 deletion may improve the cardiomyocyte survival pathway, such as the SAFE signaling pathway (i.e., phosphorylation of STAT3) [15]. The increase in Nox2 activity within the cardiovascular endothelium and leukocytes produces a simultaneous release of SO and quenching of NO (i.e., formation of peroxynitrite anion), resulting in vascular oxidative stress, endothelial dysfunction, and inflammation. Studies have shown that cardiac Nox 2 knockout mice or the delivery of Nox 2 siRNA to the heart to suppress heart Nox2 expression results in a significant 
reduction of ROS production and final infarct size, in addition to improved cardiac function following I/R [16]. These results are highly suggestive that Nox 2 is the primary source of SO release in cardiac tissue.

Despite previous research, there are still no published reports of any selective pharmacological tools that address the effects of Nox 2 in I/R injury and inflammation. Research involving apocynin, a putative Nox2 inhibitor, was shown to exert cardioprotective effects during reperfusion, however this alkaloid of Apocynum cannabinum can also exert direct antioxidant effects independent of Nox 2 inhibition $[10,17,18]$. Consequently, our research group chose to examine Nox2ds-tat (formerly known as gp91ds-tat), a more selective Nox2 peptide inhibitor, to better understand the specific role of Nox 2 in propagating oxidative stress during I/R injury. The tat portion of this peptide contains a 9-aa sequence (i.e. [H]- R-K-K-R-R-Q-R-R-R ) which facilitates Nox2ds-tat delivery into the cell. The docking sequence (i.e., C-S-T-R-R-R-Q-Q$\mathrm{L}-\mathrm{NH}_{2}$ ) specifically inhibits the assembly of cytosolic subunit $\mathrm{p} 47^{\text {phox }}$ with the membrane subunit gp91 and subsequently inhibits Nox2 assembly and activation (Figure 2) [19, 20, 21]. Moreover, in recent studies Nox2ds-tat has been shown to suppress balloon angioplasty induced SO production in carotid artery ischemia, suggesting that the effects of Nox2ds-tat could be extended to cardiomyocyte I/R injury [21, 22]. It is evident that Nox2ds-tat is a promising NADPH oxidase inhibitor, selectively targeting Nox2, which prevents the deleterious cycle of SO production and NO depletion characteristic of reperfusion-induced myocardial injury.

\section{Mechanism of Nox2ds-tat}

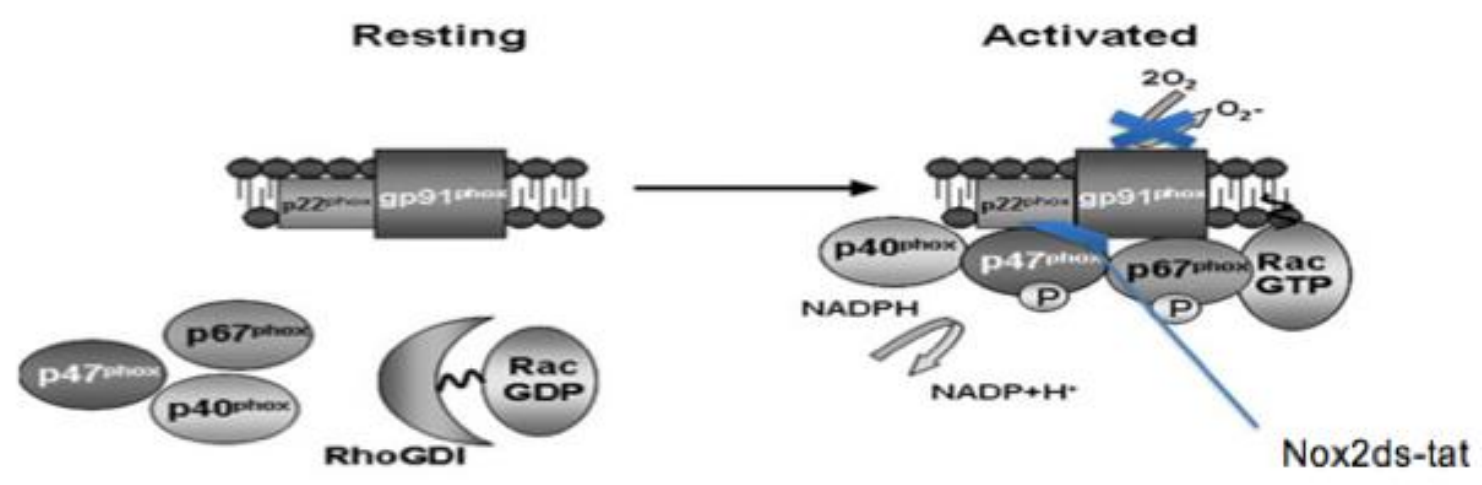

Figure 2. Schematic of Nox2ds-tat mechanism of action, whereby the blue line shows inhibition of cytosolic subunit p47phox on the gp91 Nox2 membrane component. This disallows for NADPH oxidase to assemble and the inherent production of ROS with this event, as depicted with the blue cross out. Adapted from Wilkinson et al. [40].

In this study, we first determined the dosedependent effects of Nox2ds-tat on leukocyte SO production. Next, the effects of this peptide were evaluated in myocardial and hindlimb $\mathrm{I} / \mathrm{R}$ by post-reperfused cardiac function/infarct size and $\mathrm{NO} / \mathrm{H}_{2} \mathrm{O}_{2}$, respectively. We also studied the effects of the peptide on $\mathrm{N}^{\mathrm{G}}$-L-arginine methyl ester (L-NAME) induced leukocyte-endothelial interactions in rat mesenteric venules by intravital microscopy. We predict that Nox2ds-tat will attenuate ROS in phorbol 12-myristate 13-acetate (PMA) induced leukocytes and hindlimb I/R, will 
decrease infarct size in myocardial $\mathrm{I} / \mathrm{R}$, and will attenuate leukocyte-endothelial interactions in rat mesenteric venules. Moreover, we predict that the reduction in infarct size will parallel an improvement in post reperfusion cardiac function.

\section{Methods}

\subsection{Animals}

All animal procedures were approved by the Institutional Animal Care and Use Committee at PCOM for care and use of animals. Male Sprague Dawley (SD) rats (275-325 g Charles River, Springfield, MA) were used for ex vivo and in vivo experiments and 350-400 $\mathrm{g}$ male SD rats were used for SO release assays listed below.

\subsection{Measurement of SO Release from Rat PMNs}

PMNs were isolated from male SD rats and SO release was measured spectrophotometrically (model 260 Gilford, Nova Biotech; El Cajon, CA) by the reduction of ferricytochrome $c$ [23]. The PMNs $\left(5 \times 10^{6}\right)$ were re-suspended in $450 \mu$ l PBS and incubated with ferricytochrome $c(100 \mu \mathrm{M}$, Sigma Chemical) in a total volume of $900 \mu \mathrm{l}$ PBS in the presence or absence of varying concentrations of Nox2ds-tat peptide inhibitor ([H]- R-K-K-R-R-Q-R-R-R-C-S-T-R-R-R-Q-Q$\mathrm{L}-\mathrm{NH}_{2} \quad \mathrm{MW}=2452 \mathrm{~g} / \mathrm{mol}$; Genemed Synthesis, San Antoino, TX), $10 \mu \mathrm{M}, 40 \mu \mathrm{M}$, or $80 \mu \mathrm{M}$, respectively, for $15 \mathrm{~min}$ at $37^{\circ} \mathrm{C}$ in spectrophotometric cells. The PMNs were stimulated with 100 nM PMA (MW= 616.8 $\mathrm{g} / \mathrm{mol}$; Calbiochem) in a final reaction volume of $1.0 \mathrm{ml}$. Absorbance at $550 \mathrm{~nm}$ was measured every 30 seconds for up to 360 seconds and the change in absorbance (SO release) from PMNs was determined relative to time 0 . The doseresponse curve of Nox2ds-tat on PMN SO release was used to determine a dose range that may be effective in myocardial I/R experiments.

\subsection{Isolated Rat Heart Preparation}

Male SD rats were anesthetized intraperitoneally (IP) with $60 \mathrm{mg} / \mathrm{kg}$ pentobarbital sodium and anticoagulated with $1,000 \mathrm{U}$ of sodium heparin IP. Plasma was prepared from blood isolated from the abdominal aorta of the same rat from which the heart was isolated from for each cardiac perfusion experiment. The plasma was used as the vehicle for infusion of Nox2ds-tat. The hearts were rapidly excised and perfused via the Langendorff heart preparation [24]. The aorta was cannulated and retrograde perfused with modified Krebs' buffer containing: $17.0 \mathrm{mM}$ dextrose, $120.0 \mathrm{mM} \mathrm{NaCl}, 25.0 \mathrm{mM}$ $\mathrm{NaHCO}_{3}, 2.5 \mathrm{mM} \mathrm{CaCl} 2,0.5 \mathrm{mM}$ EDTA, 5.9 $\mathrm{mM} \mathrm{KCl}$, and $1.2 \mathrm{mM} \mathrm{MgCl}_{2}$. The modified Krebs' buffer was maintained at $37^{\circ} \mathrm{C}, 80 \mathrm{mmHg}$ constant pressure, aerated with $95 \% \mathrm{O}_{2}-5 \% \mathrm{CO}_{2}$, and equilibrated $\mathrm{pH}$ between 7.3-7.4. Hearts were immersed in an $\mathrm{H}_{2} \mathrm{O}$ jacket reservoir containing $160 \mathrm{ml}$ of modified Krebs' buffer at $37^{\circ} \mathrm{C}$ to provide the preload. The preload was established by the volume of modified Krebs' buffer that entered the left ventricle. The pressure transducer catheter was inserted into the left ventricle of the heart through the mitral valve. Hearts were subjected to 15 min Krebs' buffer perfusion for stabilization in order to record an initial baseline, then $30 \mathrm{~min}$ of global ischemia by stopping perfusion, followed by a $45 \mathrm{~min}$ reperfusion period. A volume of $5 \mathrm{ml}$ of plasma (control), or plasma containing Nox 2 ds-tat $(5 \mu \mathrm{M}, 10 \mu \mathrm{M}, 40$ $\mu \mathrm{M}$, or $80 \mu \mathrm{M}$ ) was injected during the first $5 \mathrm{~min}$ of reperfusion by a side arm line proximal to the heart inflow cannula at a rate of $1 \mathrm{ml} / \mathrm{min}$. All cardiac function including coronary flow, left ventricular developed pressure ([LVDP], which is the left ventricular end-systolic pressure [LVESP] minus left ventricular end-diastolic pressure [LVEDP]), maximal and minimal rate of LVDP

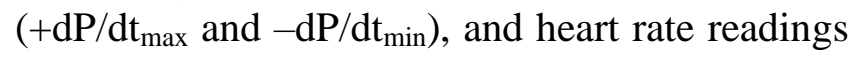
(BPM) were taken every $5 \mathrm{~min}$ from initial baseline and then throughout reperfusion. Coronary flow $(\mathrm{ml} / \mathrm{min})$ was recorded using an inline flow meter (T106, Transonic Systems, Inc., Ithaca, NY), and LVDP, LVESP, LVEDP, $+\mathrm{dP} / \mathrm{dt}_{\max },-\mathrm{dP}_{\mathrm{dt}}$ min, and $\mathrm{BPM}$ readings were recorded using a pressure transducer (SPR-524, Millar Instruments, Inc., Houston, TX). Data was recorded using a Powerlab Station acquisition system (ADInstruments, Grand Junction, CO). At the end of the experiment, the left ventricle was isolated and cross sectioned into $2 \mathrm{~mm}$ pieces from apex to base and was subjected to $1 \%$ triphenyltetrazolium chloride (TTC) staining for 
$15 \mathrm{~min}$ at $37^{\circ} \mathrm{C}$ to detect infarct size as previously described [24].

\subsection{Hindlimb $\mathrm{I} / \mathrm{R}$ in vivo procedure}

We measured blood $\mathrm{H}_{2} \mathrm{O}_{2} / \mathrm{NO}$ release in realtime from sensors placed in the femoral veins of male SD rats anesthetized with sodium pentobarbital $(60 \mathrm{mg} / \mathrm{kg}$, IP for induction and 30 $\mathrm{mg} / \mathrm{kg}$ IP for maintenance). Thereafter, one limb was subjected to I/R, while the other limb was used as a non-ischemic sham control in the same rat. The calibrated $\mathrm{H}_{2} \mathrm{O}_{2}$ or $\mathrm{NO}$ microsensors (100 $\mu \mathrm{m}$, World Precision Instruments [WPI] Inc., Sarasota, FL) were connected to a free radical analyzer (Apollo 4000, WPI Inc.) and inserted into a 24 gauge catheter placed inside each femoral vein, as previously described by Chen et al. [25] and reviewed by Young et al. [26]. Ischemia in one hindlimb was induced by clamping the femoral artery/vein for $30 \mathrm{~min}$ followed by $45 \mathrm{~min}$ of reperfusion. Nox 2 ds-tat (4.1 $\mathrm{mg} / \mathrm{kg}$ prepared in saline; $\sim 20 \mu \mathrm{M}$ in blood) or saline (non-drug control group) was administered at the beginning of reperfusion as a bolus via the jugular vein. We continuously recorded and collected the $\mathrm{H}_{2} \mathrm{O}_{2}$ or $\mathrm{NO}$ release data at $5 \mathrm{~min}$ intervals during a $15 \mathrm{~min}$ baseline, $30 \mathrm{~min}$ ischemia, and $45 \mathrm{~min}$ reperfusion period. The changes in $\mathrm{H}_{2} \mathrm{O}_{2}$ or $\mathrm{NO}$ release (in $\mathrm{pA}$ ) during $\mathrm{I} / \mathrm{R}$ are expressed as relative change to initial readings. Thereafter, the values were converted to the concentration of $\mathrm{H}_{2} \mathrm{O}_{2}(\mu \mathrm{M})$ or NO (nM) after correction to the respective calibration curves. The values recorded from the femoral vein of the I/R limb were subtracted from the values of the sham limb to yield a net difference and were recorded every $5 \mathrm{~min}$ continuously on time course graphs [25].

\subsection{Intravital Microscopy}

Male SD rats were anesthetized with 60 $\mathrm{mg} / \mathrm{kg}$ pentobarbital sodium IP and maintained with $30 \mathrm{mg} / \mathrm{kg}$ pentobarbital IP. The left carotid artery was isolated, and a PE-50 polyethylene catheter was inserted in the left carotid artery for monitoring of the mean arterial blood pressure (MABP) via BP-1 Pressure Monitor (WPI Inc, Sarasota, FL). After abdominal laparotomy, a loop of ileal mesentery was exteriorized and placed in a temperature controlled Plexiglas chamber $\left(37^{\circ} \mathrm{C}\right)$ for adequate superfusion of the test solutions [27]. The mesentery was placed over a Plexiglas pedestal in the observation chamber for visualization under a Nikon Eclipse microscope (Nikon Co., Japan). The microcirculation was recorded with Image Pro, MDA (Media Cybernetics, Bethesda, MD) and leukocyte-endothelial interactions were analyzed offline.

The rats were allowed to stabilize for $30 \mathrm{~min}$ with superfusion of Krebs' buffer after surgery. After stabilization, a non-branched postcapillary venule was chosen for observation. An initial recording was made to establish basal values for leukocyte rolling, adherence, and transmigration. The mesentery then was superfused with the experimental test solutions for $120 \mathrm{~min}$. Test solutions included Krebs' buffer alone, $50 \mu \mathrm{M}$ LNAME alone, and $50 \mu \mathrm{M}$ L-NAME in the presence of Nox $2 \mathrm{ds}$-tat $(5 \mu \mathrm{M}$ or $20 \mu \mathrm{M})$. All drugs were dissolved into the Krebs' buffer. The solution was aerated with $95 \% \mathrm{~N}_{2}-5 \% \mathrm{CO}_{2}$ and equilibrated at a pH of 7.3 to 7.4 at $37{ }^{\circ} \mathrm{C}$. Two min video recordings were made at baseline, 30 min, $60 \mathrm{~min}, 90 \mathrm{~min}$, and $120 \mathrm{~min}$ after superfusion of the test solutions for quantification of leukocyte rolling, adherence, and transmigration [24, 27].

\subsection{Hematoxylin and Eosin (H\&E) Staining}

After the experiment, the loop of the ileal mesentery that was superfused during the experiment was removed and quickly stored in $4 \%$ paraformaldehyde for histological analysis of leukocyte adherence and transmigration by $H \& E$ staining. Three representative sections of the ileal mesentery from Krebs' buffer, $50 \mu \mathrm{M}$ L-NAME, and $50 \mu \mathrm{M}$ L-NAME in the presence of Nox $2 \mathrm{ds}-$ tat $(5 \mu \mathrm{M}$ or $20 \mu \mathrm{M})$ were selected for histological analysis. Tissue samples were selected from experiments representative of the group mean of intravital microscopy (Table 2). The tissue was embedded in paraffin and sectioned into $4.5 \mu \mathrm{m}$ serial sections and placed onto glass slides. Sections were deparaffinized and rehydrated, then stained with H\&E [27]. Under light microscopy, leukocyte adherence and transmigration was counted in areas containing 
venules/arterioles within the serosa and the mesentery, and expressed as adhered and transmigrated leukocytes $/ \mathrm{mm}^{2}$ in tissue.

\subsection{Statistical Analysis}

All data in the text and figures are presented as means \pm standard error of the mean (S.E.M.) The data was analyzed by analysis of variance (ANOVA) using post hoc analysis with the Student-Newman-Keuls test for all experiments except for hindlimb I/R in which a student's t-test was used. A $p$ value of $<0.05$ was considered to be statistically significant.

\section{Results}

\subsection{PMN SO release}

PMA is a broad-spectrum activator of protein kinase $\mathrm{C}$ (PKC), which is essential in promoting NADPH oxidase assembly at the PMN membrane to generate SO release [28].We found that Nox2ds-tat exhibited a dose-dependent reduction in PMA-stimulated PMN SO release (Figure 3). Doses of Nox2ds-tat $(10 \mu \mathrm{M}$ and 40 $\mu \mathrm{M})$ did not significantly decrease PMN SO release, whereas a dose of $80 \mu \mathrm{M}$ significantly inhibited PMA-induced SO release by $37 \pm 7 \%$ ( $\mathrm{p}<0.05$ compared to PMA alone). The data generated from this assay was used to test a similar dose range of Nox2ds-tat in isolated rat heart I/R experiments.

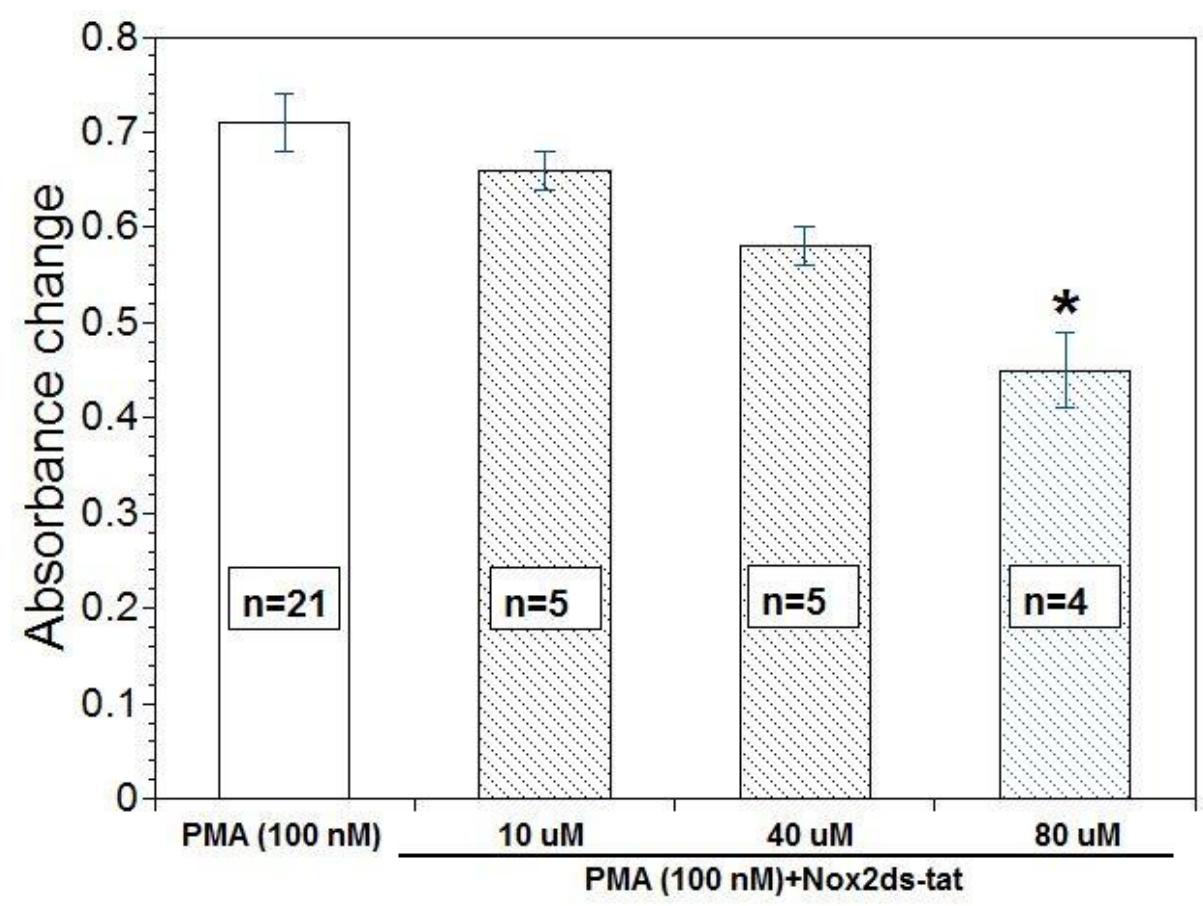

Figure 3. PMA (100 nM) induced SO release in PMNs; peak response read at 360s post stimulation. Nox2ds-tat dose dependently inhibited SO release from PMNs by $37 \pm 7 \%(80 \mu \mathrm{M}, \mathrm{n}=4)$ when compared to PMNs treated with PMA alone. (*p<0.05 vs. PMA control)

\subsection{Cardiac function and infarct size}

Nox2ds-tat given at reperfusion dosedependently attenuated $\mathrm{I} / \mathrm{R}$ induced cardiac contractile dysfunction and recovered postreperfused LVDP to $47 \pm 7 \%(5 \mu \mathrm{M}, \mathrm{n}=7), 69 \pm$ $13 \%(10 \mu \mathrm{M}, \mathrm{n}=6, \mathrm{p}<0.05), 68 \pm 7 \%(40 \mu \mathrm{M}$, $\mathrm{n}=6, \mathrm{p}<0.05)$, and $77 \pm 7 \%(80 \mu \mathrm{M}, \mathrm{n}=6, \mathrm{p}<0.05)$ of initial LVDP at 45 min post-reperfusion when compared to control $\mathrm{I} / \mathrm{R}$ hearts that only recovered to $46 \pm 6 \%(n=14)$ (Table 1$)$. Initial baseline values for cardiac function parameters did not differ significantly among groups. 
Table 1. Cardiac function parameters among different experimental groups.

\begin{tabular}{|c|c|c|c|c|c|}
\hline Cardiac Parameters & $\begin{array}{l}\text { Control I/R } \\
\quad(n=14)\end{array}$ & $\begin{array}{c}\mathrm{I} / \mathrm{R}+ \\
\text { Nox2ds-tat } 5 \\
\mu \mathrm{M} \\
(\mathrm{n}=7)\end{array}$ & $\begin{array}{c}\mathrm{I} / \mathrm{R}+ \\
\text { Nox2ds-tat } \\
10 \mu \mathrm{M} \\
(\mathrm{n}=6)\end{array}$ & $\begin{array}{c}\mathrm{I} / \mathrm{R}+ \\
\text { Nox } 2 \mathrm{ds}-\mathrm{tat} \\
40 \mu \mathrm{M} \\
(\mathrm{n}=6)\end{array}$ & $\begin{array}{c}\mathrm{I} / \mathrm{R}+ \\
\text { Nox2ds-tat } \\
80 \mu \mathrm{M} \\
(\mathrm{n}=6)\end{array}$ \\
\hline Initial LVDP (mmHg) & $87 \pm 3.5$ & $91 \pm 3.1$ & $89 \pm 3.4$ & $92 \pm 3.9$ & $88 \pm 3.3$ \\
\hline Final LVDP $(\mathrm{mmHg})$ & $40 \pm 5.0$ & $43 \pm 6.6$ & $61 \pm 12.1 *^{\#}$ & $63 \pm 6.2 *$ & $68 \pm 6.2 *^{\#}$ \\
\hline Initial LVESP (mmHg) & $99 \pm 3.8$ & $101 \pm 3.9$ & $105 \pm 4.8$ & $103 \pm 4.6$ & $101 \pm 3.7$ \\
\hline Final LVESP (mmHg) & $100 \pm 5.3$ & $108 \pm 5.7$ & $107 \pm 11.9$ & $110 \pm 7.5$ & $124 \pm 9.7$ \\
\hline Initial LVEDP (mmHg) & $11 \pm 1.0$ & $9.4 \pm 1.3$ & $16 \pm 2.0$ & $11 \pm 1.3$ & $13 \pm 0.7$ \\
\hline Final LVEDP(mmHg) & $61 \pm 5.1$ & $64 \pm 4.2$ & $46 \pm 6.1^{\#}$ & $47 \pm 7.5^{\#}$ & $56 \pm 5.6$ \\
\hline Initial $+\mathrm{dP} / \mathrm{dt}_{\max }(\mathrm{mmHg} / \mathrm{sec})$ & $2259 \pm 71$ & $2335 \pm 61$ & $2333 \pm 66$ & $2346 \pm 77$ & $2277 \pm 79$ \\
\hline Final $+\mathrm{dP} / \mathrm{dt}_{\max }(\mathrm{mmHg} / \mathrm{sec})$ & $894 \pm 105$ & $832 \pm 124$ & $1285 \pm 232^{\#}$ & $1258 \pm 120 * \#$ & $1413 \pm 100 * \# \#$ \\
\hline Initial $-\mathrm{dP} / \mathrm{dt}_{\min }(\mathrm{mmHg} / \mathrm{sec})$ & $-1510 \pm 67$ & $-1616 \pm 98$ & $-1607 \pm 84$ & $-1550 \pm 124$ & $-1524 \pm 106$ \\
\hline Final $-\mathrm{dP} / \mathrm{dt}_{\min }(\mathrm{mmHg} / \mathrm{sec})$ & $-704 \pm 65$ & $-660 \pm 136$ & $-879 \pm 187$ & $-939 \pm 108$ & $-1116 \pm 146^{*}$ \\
\hline $\begin{array}{lll}\text { Initial } & \text { coronary } & \text { flow } \\
(\mathrm{ml} / \mathrm{min}) & & \\
\end{array}$ & $16.2 \pm 1.2$ & $14.4 \pm 0.64$ & $18.1 \pm 1.4$ & $18.0 \pm 2.5$ & $15.2 \pm 1.0$ \\
\hline Final coronary flow (ml/min) & $7.9 \pm 0.64$ & $7.9 \pm 0.70$ & $9.2 \pm 1.5$ & $9.3 \pm 1.7$ & $9.5 \pm 1.5^{\#}$ \\
\hline Initial Heart Rate (BPM) & $271 \pm 12.8$ & $277 \pm 12.3$ & $280 \pm 7.8$ & $272 \pm 8.8$ & $265 \pm 3.2$ \\
\hline Final Heart Rate (BPM) & $246 \pm 18.8$ & $234 \pm 19.9$ & $230 \pm 10.5$ & $249 \pm 13.6$ & $237 \pm 11.9$ \\
\hline
\end{tabular}

${ }^{*} \mathrm{p}<0.05$ vs control I/R final cardiac function parameters; ${ }^{\#} \mathrm{p}<0.05,{ }^{\#} \mathrm{p}<0.01$ vs Nox 2 ds-tat $5 \mu \mathrm{M}$

Similarly, Nox2ds-tat reduced infarct size/area-at-risk when compared to the I/R control group (Figure 4, Panel A-B). The cross section for the $\mathrm{I} / \mathrm{R}$ control group shows the majority of the infarct in the mid-wall area, whereas the Nox2ds-tat treated I/R hearts showed less infarct area (Figure 4, Panel A). Figure 4, Panel B shows the ratio of this tissue at risk. When compared to the $\mathrm{I} / \mathrm{R}$ control group (46 \pm $2 \%$ ), there was a significant decrease in total infarct size in hearts treated with Nox2ds-tat $30 \pm$ $4 \%(5 \mu \mathrm{M}), 15 \pm 1.4 \%(10 \mu \mathrm{M}), 23 \pm 2 \%(40$ $\mu \mathrm{M})$, and $19 \pm 1.6 \%(80 \mu \mathrm{M})(\mathrm{p}<0.01$ for all groups). Moreover, the $10 \mu \mathrm{M}$ and $80 \mu \mathrm{M}$ doses showed significantly less infarct size compared to the $5 \mu \mathrm{M}$ dose $(\mathrm{p}<0.01$ and $\mathrm{p}<0.05$ respectively), suggesting a dose-dependent effect of Nox2ds-tat on infarct size (Figure 4, Panel A-B).

Other cardiac function parameters are illustrated in Table 1. Of interest, Nox2ds-tat dose-dependently recovered post-reperfused final $+\mathrm{dP} / \mathrm{dtmax}$ by $36 \pm 5.3 \%(5 \mu \mathrm{M}), 55 \pm 10 \%(10$ $\mu \mathrm{M}), 54 \pm 4 \%(40 \mu \mathrm{M}, \mathrm{p}<0.05), 62 \pm 4 \%(80 \mu \mathrm{M}$, $\mathrm{p}<0.05)$ at $45 \mathrm{~min}$ reperfusion compared to control I/R hearts that only recovered to $40 \pm 5 \%$. Sham hearts $(n=6)$ were not subjected to I/R and maintained cardiac function parameters and flow by $>90 \%$ and had $<5 \%$ infarct size/area-at- risk throughout the experimental time-course (data not shown). 


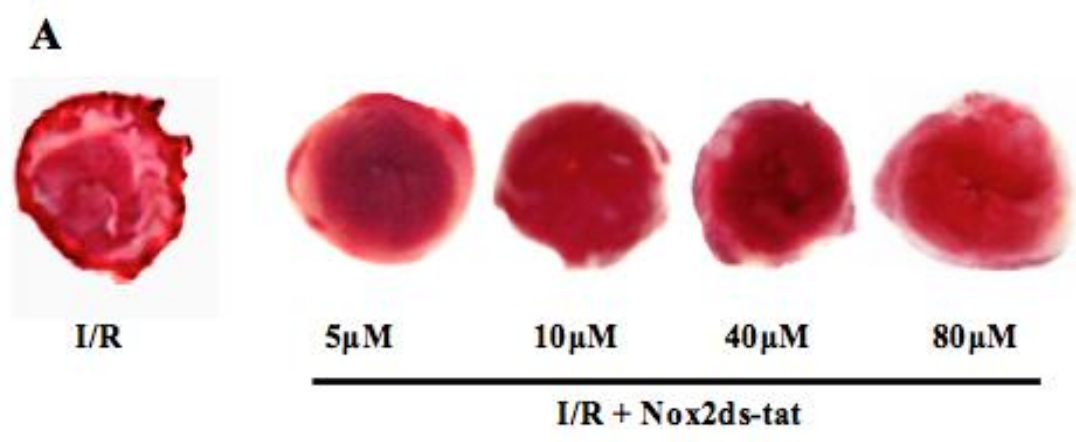

B

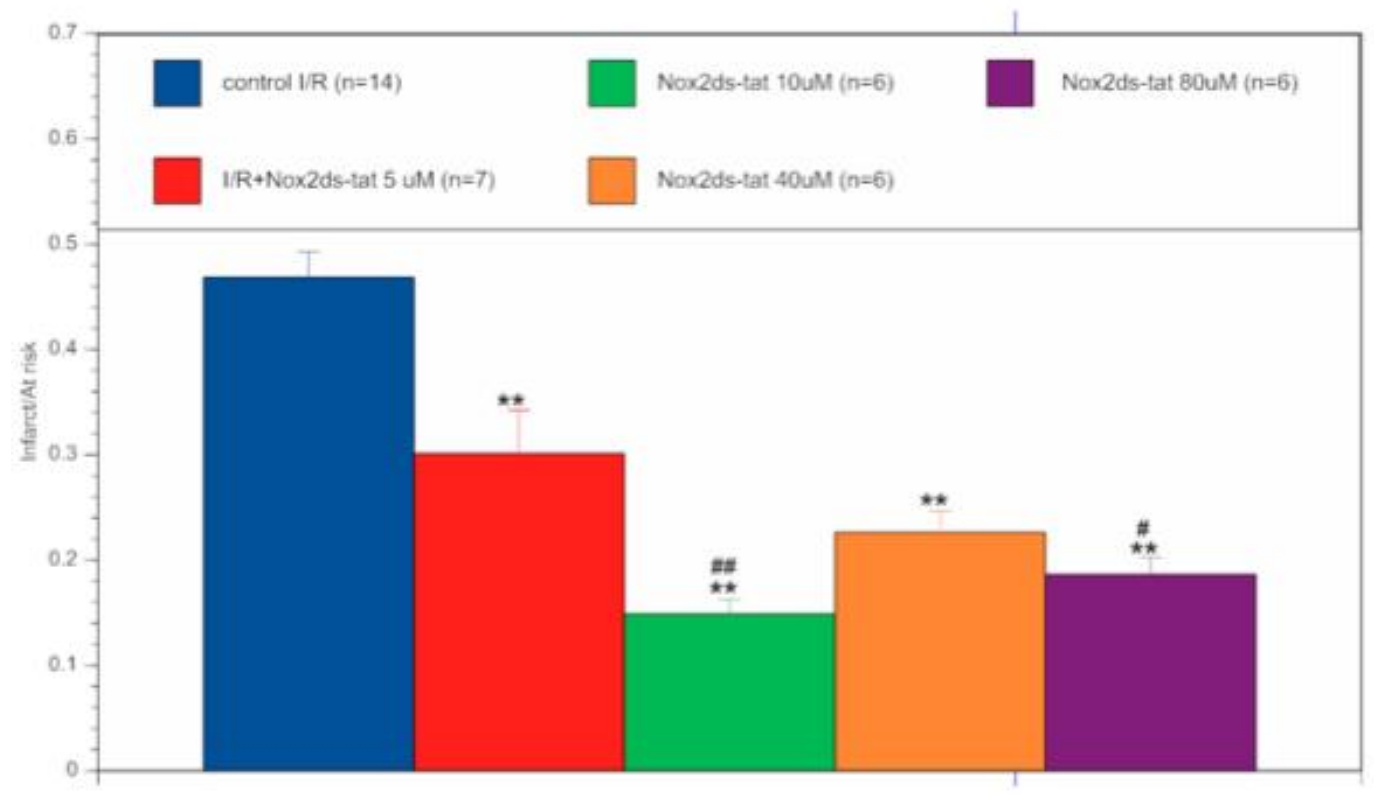

Figure 4. Panel A: Representative images of TTC staining and percentage of left ventricular heart tissue at risk among different experimental groups. Viable tissue stains red, infarcted tissue did not retain TTC staining. Nox2ds-tat dose dependently attenuated infarct size. Panel B: Ratio of left ventricular heart tissue at risk for myocardial dysfunction out of total tissue weight, as determined by TTC staining of representative heart sections. When compared to the I/R control group which had an infarct size of $46 \pm 2 \%$, there was a significant decrease in total infarct size in heart sections treated with Nox2ds-tat. Nox2ds-tat dose-dependently attenuated infarct sizes to $30 \pm 4 \%(5 \mu \mathrm{M}, \mathrm{n}=7), 15 \pm 1.4 \%(10$ $\mu \mathrm{M}, \mathrm{n}=6), 23 \pm 2 \%(40 \mu \mathrm{M}, \mathrm{n}=6)$, and $19 \pm 1.6 \%(80 \mu \mathrm{M}, \mathrm{n}=6)(\mathrm{p}<0.01$ vs. control tissue, $\mathrm{n}=14)$. There was also a significant decrease in infarct size observed in $10 \mu \mathrm{M}(\mathrm{p}<0.01)$ and $80 \mu \mathrm{M}(\mathrm{p}<0.05)$ compared to $5 \mu \mathrm{M}$ Nox2ds-tat. $(* * \mathrm{p}<0.01$ vs control I/R, \#p $<0.05$ vs Nox 2 ds-tat $5 \mu \mathrm{M}$, \#\#p<0.01 vs Nox $2 \mathrm{ds}-$ tat $5 \mu \mathrm{M})$

\subsection{Hindlimb I/R in vivo}

\subsubsection{Nox2ds-tat reduced blood $\mathrm{H}_{2} \mathrm{O}_{2}$ levels}

The blood $\mathrm{H}_{2} \mathrm{O}_{2}$ values in the $\mathrm{I} / \mathrm{R}$ hindlimb of saline controls significantly increased to $1.7 \pm 0.3$ $\mu \mathrm{M}$ (15 min post-reperfusion) above sham values. Thereafter, a relative difference of $1.2-1.4 \mu \mathrm{M}$ between the I/R and sham limbs was maintained throughout the remainder of reperfusion (Figure 5, Panel A). By contrast, Nox2ds-tat (4.1 mg/kg: $\sim 20 \mu \mathrm{M}$ in blood) treated animals in the $\mathrm{I} / \mathrm{R}$ hindlimb did not significantly differ from the sham hindlimb throughout reperfusion (Figure 5, Panel B). The relative difference in blood $\mathrm{H}_{2} \mathrm{O}_{2}$ levels between I/R and sham limbs in Nox2ds-tat treated animals versus saline controls illustrate that the Nox2ds-tat treated animals exhibited a significant reduction in the $\mathrm{I} / \mathrm{R}$ induced effect on blood $\mathrm{H}_{2} \mathrm{O}_{2}$ by $1.43 \pm 0.2 \mu \mathrm{M}$ at the end of reperfusion (Figure 5, Panel C). 

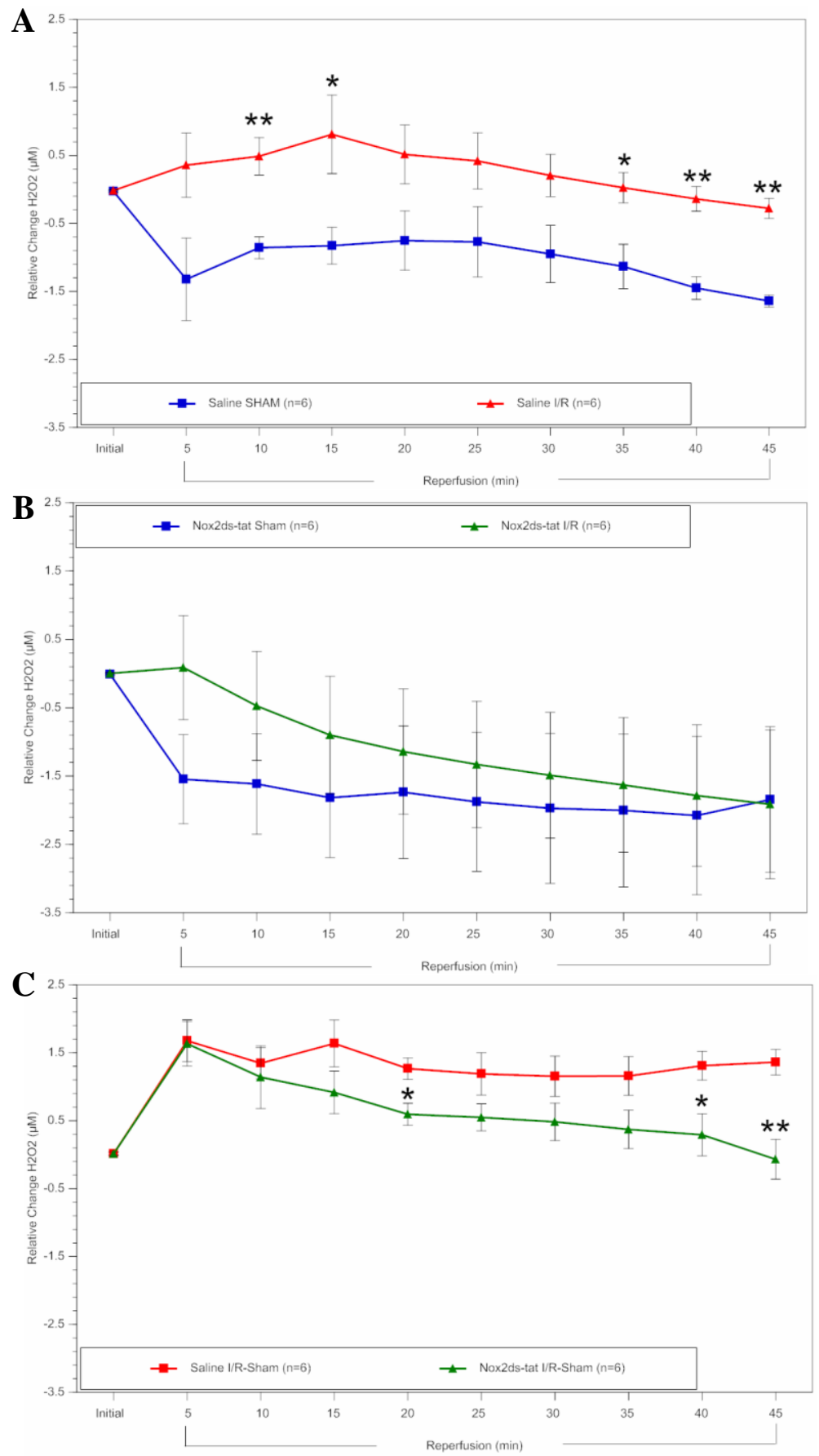

Figure 5. Panel A: Relative difference in measured blood $\mathrm{H}_{2} \mathrm{O}_{2}$ between $\mathrm{I} / \mathrm{R}$ and sham femoral veins in saline controls. The saline I/R vein showed a significant increase in blood $\mathrm{H}_{2} \mathrm{O}_{2}$ by $1.7 \pm 0.3 \mu \mathrm{M}(5 \mathrm{~min})$ relative to the sham femoral vein. This increase above sham femoral vein values was maintained throughout reperfusion, stabilizing at $1.4 \pm 0.2 \mu \mathrm{M}$ (45 min). (*p<0.05, **p<0.01 vs. sham I/R femoral vein). Panel B: Relative difference in measured blood $\mathrm{H}_{2} \mathrm{O}_{2}$ between I/R and sham femoral veins in Nox2ds-tat $(4.1 \mathrm{mg} / \mathrm{kg} ; \sim 20 \mu \mathrm{M})$ treated rats. The I/R femoral vein treated with Nox2ds-tat showed a transient increase in $\mathrm{H}_{2} \mathrm{O}_{2}$ when compared to the sham femoral vein. However, this difference between the two limbs decreased throughout the remainder of the experiment, ending at $\sim 0 \mu \mathrm{M}$. The measured values in the two groups were not statistically different at any point in the experiment. Panel C: Relative difference in measured blood $\mathrm{H}_{2} \mathrm{O}_{2}$ betweenNox2ds-tat $\left(\mathrm{I} / \mathrm{R}_{\mathrm{Nox} 2 \mathrm{ds} \text {-tat }}-\right.$ sham $_{\mathrm{Nox} 2 \mathrm{ds} \text {-tat }}$ values) and saline controls $\left(\mathrm{I} / \mathrm{R}_{\text {saline }}-\right.$ sham $_{\text {saline }}$ values). Nox2ds-tat infusion at reperfusion significantly decreased the blood $\mathrm{H}_{2} \mathrm{O}_{2}$ concentration when compared to rats infused with saline. At the end of the $45 \mathrm{~min}$ reperfusion period there was a significant reduction of $1.4 \mu \mathrm{M}$ between blood $\mathrm{H}_{2} \mathrm{O}_{2}$ measured in Nox2ds-tat $20 \mu \mathrm{M}$ treated rats relative to saline control. $(* \mathrm{p}<0.05$, $* * \mathrm{p}<0.01$ vs. saline treated femoral veins). 

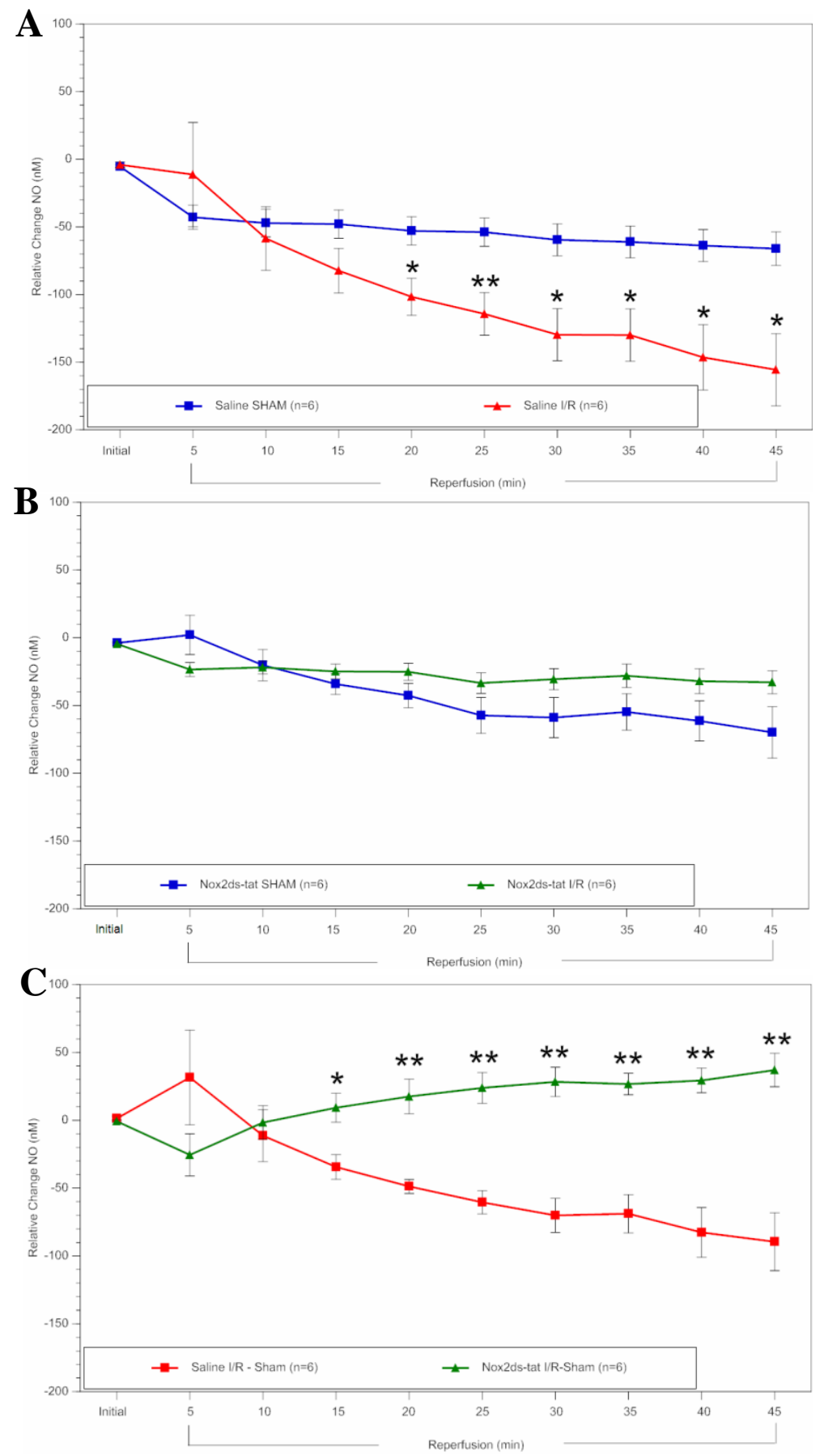

Figure 6. Panel A: Relative difference in measured blood NO between I/R and sham femoral veins in saline controls. Overall, the I/R femoral vein showed a significant decrease in NO concentration, stabilizing at a difference of $90 \pm 21$ $\mathrm{nM}$ when compared to the sham femoral vein at the end of the 45 min reperfusion period. $\left({ }^{*} \mathrm{p}<0.05\right.$, $* * \mathrm{p}<0.01$ vs. sham I/R femoral vein) Panel B: Relative difference in measured blood NO between I/R and sham femoral veins in Nox $2 \mathrm{ds}-$ tat $(4.1 \mathrm{mg} / \mathrm{kg} ; \sim 20 \mu \mathrm{M})$ treated rats. In Nox2ds-tat treated animals, the $\mathrm{I} / \mathrm{R}$ femoral vein resulted in $37 \pm 12 \mathrm{nM}$ higher blood NO concentration than the sham limb at the end of the 45 min reperfusion period, however this difference was not statistically significant $\left({ }^{*} \mathrm{p}<0.05,{ }^{*} \mathrm{p}<0.01\right.$ vs. sham I/R femoral vein). Panel C: Relative difference in measured blood NO in Nox2ds-tat ( $\mathrm{I} / \mathrm{R}_{\mathrm{Nox} 2 \mathrm{ds}-\mathrm{tat}}-$ sham $_{\text {Nox2ds-tat }}$ values $)$ and saline controls $\left(\mathrm{I} / \mathrm{R}_{\text {saline }}-\right.$ sham $_{\text {saline }}$ values $)$. Nox $2 \mathrm{ds}$-tat given at reperfusion significantly increased the total blood NO concentration when compared to saline controls. At the end of the $45 \mathrm{~min}$ reperfusion period there was a significant increase of $127 \mathrm{nM}$ in blood NO in Nox2ds-tat treated animals relative to saline controls. $(* \mathrm{p}<0.05, * * \mathrm{p}<0.01$ vs. saline treated femoral veins). 


\subsubsection{Nox2ds-tat prevented the decrease in blood NO levels}

In saline controls, blood NO levels steadily decreased in the $\mathrm{I} / \mathrm{R}$ limb throughout the reperfusion period, leading to significantly lower blood NO bioavailability ( $90 \mathrm{nM}$ below sham) as early as $20 \mathrm{~min}$ into the reperfusion period (Figure 6, Panel A). By contrast, blood NO in the I/R hindlimb of Nox2ds-tat $(4.1 \mathrm{mg} / \mathrm{kg}: \sim 20 \mu \mathrm{M}$ in blood) treated animals did not significantly differ from sham hindlimb values during the reperfusion period. While a linear trend close to sham values was observed, the Nox2ds-tat treated group's blood NO levels did rise to $37 \mathrm{nM}$ above sham values at the end of reperfusion (Figure 6, Panel B). The relative difference in blood NO levels between I/R and sham limbs in Nox2ds-tat treated animals versus saline controls illustrate that the Nox2ds-tat treated animals exhibited a significant increase in the $\mathrm{I} / \mathrm{R}$ induced effect on $\mathrm{NO}$ release by $127 \mathrm{nM}$ at the end of reperfusion (Figure 6, Panel C).

\subsection{L-NAME induced Leukocyte endothelial interactions}

\subsubsection{Intravital Microscopy}

There was no significant difference among initial baseline values in leukocyte rolling, adherence, and transmigration among all study groups. In all parameters, the Krebs' buffer group did not significantly change from baseline. LNAME $(50 \mu \mathrm{M})$ significantly increased leukocyte rolling, adherence, and transmigration when compared to Krebs' at $\mathrm{T}=120 \mathrm{~min}$ by $82 \pm 11$ $(\mathrm{p}<0.01), 22 \pm 5(\mathrm{p}<0.01)$, and $21 \pm 4(\mathrm{p}<0.01)$, respectively (Table 2$)$. Nox 2 ds-tat $(5 \mu \mathrm{M})$ did not significantly attenuate L-NAME induced leukocyte-endothelial interactions except for final transmigration $(\mathrm{p}<0.05)$. By contrast, Nox2ds-tat $(20 \mu \mathrm{M})$ significantly decreased the L-NAME induced effect by 3-5 fold on all parameters $(\mathrm{p}<0.01)$ (Table 2).

Table 2. The comparision of initial and final (120 min of reperfusion) leukocyte rolling, adherence and transmigration between Krebs', L-NAME, and L-NAME + Nox2ds-tat $(5 \mu \mathrm{M}, 20 \mu \mathrm{M})$ groups in rat mesenteric venules.

\begin{tabular}{|l|c|c|c|c|}
\hline Intravital microscopy Parameters & $\begin{array}{c}\text { Krebs' } \\
(\mathrm{n}=6)\end{array}$ & $\begin{array}{c}\text { L-NAME } \\
(\mathrm{n}=5)\end{array}$ & $\begin{array}{c}\text { L-NAME }+ \\
\text { Nox2ds-tat 5 } \mu \mathrm{M} \\
(\mathrm{n}=4)\end{array}$ & $\begin{array}{c}\text { L-NAME + } \\
\text { Nox2ds-tat } 20 \mu \mathrm{M} \\
(\mathrm{n}=6)\end{array}$ \\
\hline Initial Rolling (number/min) & $8 \pm 3$ & $11 \pm 3$ & $13 \pm 3$ & $8 \pm 2$ \\
\hline Final Rolling (number/min) & $16 \pm 5$ & $82 \pm 11^{* *}$ & $72 \pm 13^{* *}$ & $16 \pm 6^{\# \#++}$ \\
\hline Initial Adherence (number/100um) & $2 \pm 2$ & $1 \pm 0$ & $3 \pm 0$ & $1 \pm 1$ \\
\hline Final Adherence (number/100um) & $4 \pm 2$ & $22 \pm 5^{* *}$ & $17 \pm 1^{*}$ & $1 \pm 0$ \\
\hline Initial Transmigration (number) & $1 \pm 0$ & $1 \pm 0$ & $1 \pm 0$ & $4 \pm 2^{\# \#}$ \\
\hline Final Transmigration (number) & $1 \pm 0$ & $21 \pm 4^{* *}$ & $9 \pm 1^{* \# \#}$ & \\
\hline
\end{tabular}

${ }^{*} P<0.05,{ }^{* *} P<0.01$ compared to Krebs' group; ${ }^{\#} \mathrm{P}<0.05,{ }^{\#} \mathrm{P}<0.01$ compared to L-NAME; ${ }^{++} \mathrm{P}<0.01$ compared to LNAME + Nox2ds-tat $5 \mu \mathrm{M}$

\subsubsection{H\&E Staining}

The Krebs'control group exhibited only $73 \pm$ 33 and $62 \pm 30$ leukocytes $/ \mathrm{mm}^{2}$ of mesenteric tissue. These values represent basal numbers of leukocyte adherence and transmigration in this tissue bed respectively. L-NAME treatment exhibited a marked increase ( 4-fold) in leukocyte vascular adherence and transmigration compared to Krebs' buffer $(299 \pm 23$ and $271 \pm$ 26 leukocytes $/ \mathrm{mm}^{2}$ of tissue, respectively, $\mathrm{p}<0.01$ for both values). Nox2ds-tat dose-dependently attenuated the L-NAME induced effect on leukocyte adherence $(199 \pm 13$ for $5 \mu \mathrm{M}$ at $\mathrm{p}<0.05$ and $83 \pm 9$ for $20 \mu \mathrm{M} \mathrm{p}<0.01)$ and 
transmigration $(134 \pm 17$ for $5 \mu \mathrm{M}$ and $55 \pm 9$ for $20 \mu \mathrm{M}, \mathrm{p}<0.01$ for both values). It should be noted that the $20 \mu \mathrm{M}$ dose diminished adherence and transmigration down to initial values (Figure 7, Panel A-B).

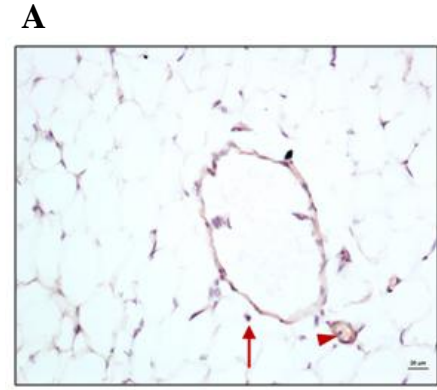

Krebs

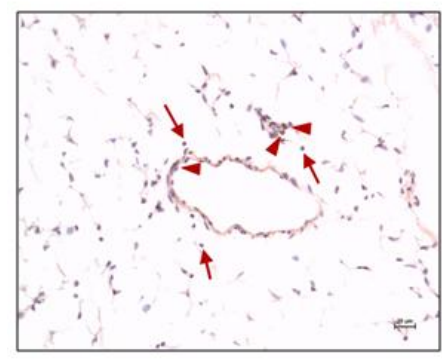

L-NAME + Nox2ds-tat 5 MM

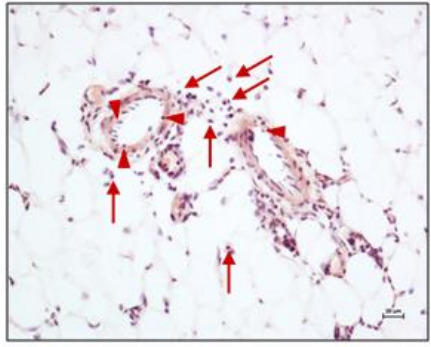

L-NAME

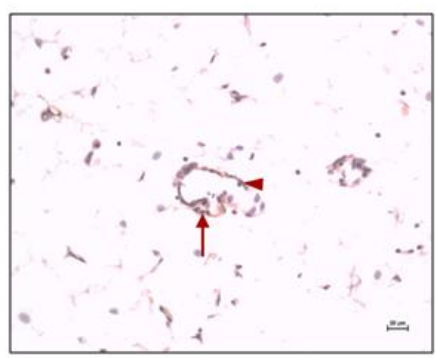

L-NAME + Nox2ds-tat $20 \mu M$

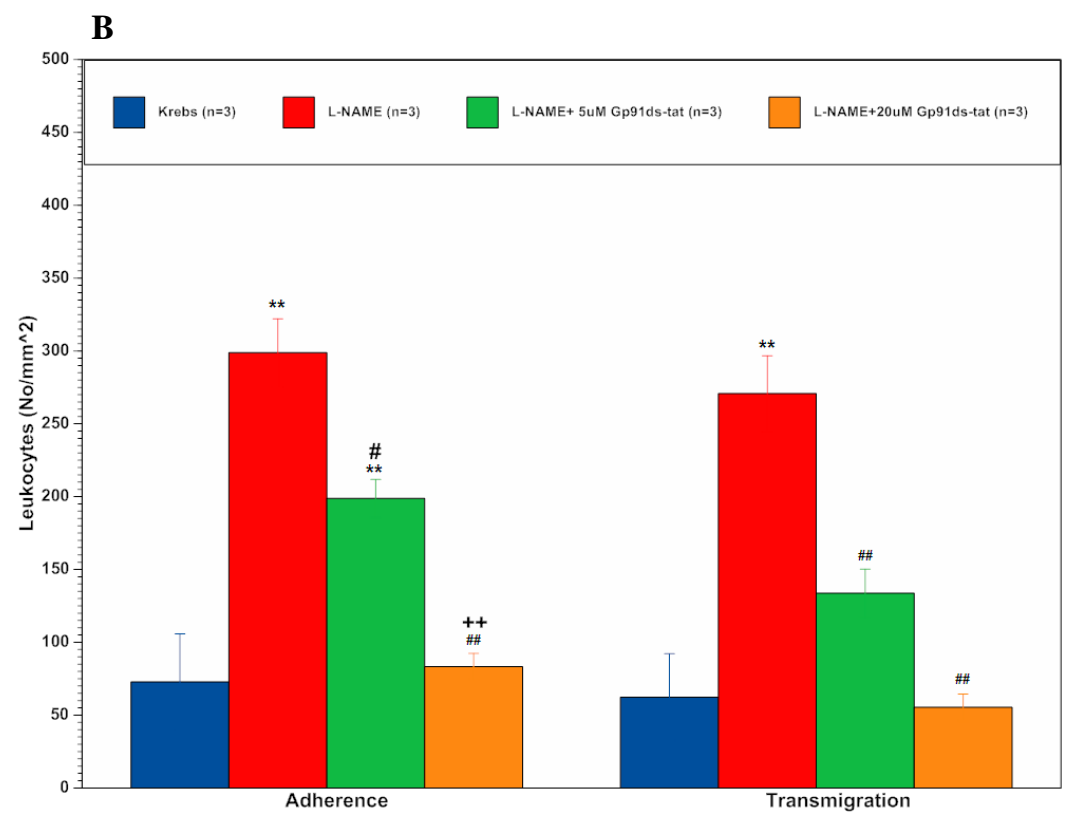

Figure 7. Panel A: H\&E stain of mesenteric tissue with representative view (20x) of leukocyte adherence and transmigration. When compared to Krebs' control buffer, L-NAME $(50 \mu \mathrm{M})$ treated tissue displayed a noticeable increase in leukocyte endothelium adherence and transmigration to the injured site. Nox2ds-tat $(20 \mu \mathrm{M})$ treated tissue visibly decreased both adherence and transmigrated of leukocytes when compared to L-NAME. Arrowhead indicates adherence and arrow indicate transmigration (20x, scale bar; $20 \mu \mathrm{m})$. Panel B: Graph of leukocyte adherence and transmigration as determined by H\&E staining of representative rat mesenteric tissue. When compared to Krebs' control buffer, L-NAME treated tissue displayed a significant increase in leukocyte endothelium adherence and transmigration to injured site $(* * \mathrm{p}<0.01$ from Krebs'). Nox2ds-tat dose dependently decreased leukocyte adherence and transmigration compared to L-NAME treated tissue (\#p<0.05, \#\#p<0.01 from to L-NAME). There was also a significant difference in adherence between the $5 \mu \mathrm{M}$ and $20 \mu \mathrm{M}$ doses $\left({ }^{++} \mathrm{p}<0.01\right.$ vs Nox 2 ds-tat $\left.5 \mu \mathrm{M}\right)$ 


\section{Discussion}

\subsection{Summary of Findings}

The major findings of this study are as follows: 1. Nox2ds-tat attenuated PMA-induced leukocyte SO release up to $37 \pm 7 \%(80 \mu \mathrm{M})$ compared to untreated controls $(\mathrm{p}<0.05) ; 2$. In isolated perfused hearts, Nox2ds-tat attenuated infarct size/area-at-risk by $30 \pm 4 \%(5 \mu \mathrm{M}), 15 \pm$ $1.4 \%(10 \mu \mathrm{M}), 23 \pm 2 \%(40 \mu \mathrm{M})$, and $19 \pm 1.6 \%$ $(80 \mu \mathrm{M})$ when compared to control $\mathrm{I} / \mathrm{R}$ hearts that had an infarct size/area-at-risk of $46 \pm 2 \%$ (all doses $\mathrm{p}<0.01$ vs. $\mathrm{I} / \mathrm{R}$ control); 3 . Nox 2 ds-tat increased post-reperfused LVDP to $47 \pm 7 \%$ (5 $\mu \mathrm{M}), 69 \pm 14 \%(10 \mu \mathrm{M} ; \mathrm{p}<0.05), 68 \pm 7 \%(40$ $\mu \mathrm{M} ; \mathrm{p}<0.01)$ and $77 \pm 7 \%(80 \mu \mathrm{M} ; \mathrm{p}<0.05)$ when compared to control I/R hearts that were $46 \pm 6 \%$; 4. Nox2ds-tat significantly decreased postreperfused ( $45 \mathrm{~min}$ ) blood $\mathrm{H}_{2} \mathrm{O}_{2}$ levels by $1.4 \mu \mathrm{M}$ below saline controls $(p<0.01)$ in hindlimb I/R; 5 . Nox2ds-tat significantly increased postreperfused (45 min) blood NO by $127 \mathrm{nM}$ above saline controls $(\mathrm{p}<0.01)$ in hindlimb $\mathrm{I} / \mathrm{R} ; 6$. Nox2ds-tat $(20 \mu \mathrm{M})$ significantly attenuated LNAME induced leukocyte-endothelial interactions in rat mesenteric venules by 3 -to-5 fold, and reduced leukocyte rolling, adherence, and transmigration back to the initial baseline values recorded. These results suggest that Nox2ds-tat exerted post-reperfused cardioprotective and anti-inflammatory effects possibly by inhibiting ROS release generated by Nox2.

\subsection{Relevance of Study Findings}

\subsubsection{Cardiac Function}

Although there was a positive correlation between the concentration of Nox2ds-tat and restoration of LVDP, the increase in LVDP in the $80 \mu \mathrm{M}$ dose was primarily related to an increase in LVESP as opposed to a decrease in LVEDP, which was seen in the $10 \mu \mathrm{M}$ and $40 \mu \mathrm{M}$ doses and also observed in our previous studies [17, 24]. This point is significant since this finding is unprecedented in our ex vivo isolated perfused rat model exposed to $30 \mathrm{~min}$ of ischemia, which is typically characterized by an abrupt increase in LVEDP (e.g., 90mmHg) within the first few min of reperfusion and only relaxing to $\sim 60 \mathrm{mmHg}$ by the end of the reperfusion time period (45 $\mathrm{min}$ ) in control $\mathrm{I} / \mathrm{R}$ hearts. As seen in the $10 \mu \mathrm{M}$ and $40 \mu \mathrm{M}$ doses, the drug was able to decrease LVEDP (while maintaining a similar or slightly elevated LVESP) and thus increase the LVDP when compared to control $\mathrm{I} / \mathrm{R}$ hearts. The increase in LVESP in the $80 \mu \mathrm{M}$ dose suggests that the heart was able to produce a contraction strong enough to compensate for the increased LVEDP. We believe that at this high dose $(80$ $\mu \mathrm{M})$, it caused a shift in the cardiac contractility parameters wherein, there is both an increase in the LVEDP and LVESP when compared to the $10 \mu \mathrm{M}$ and $40 \mu \mathrm{M}$ doses (Table 1). It should be noted that the increase in post-reperfused LVDP for the $80 \mu \mathrm{M}$ dose when compared to control I/R hearts is due to the LVESP increasing more than LVEDP. We speculate that these results are indicative of reduced Nox2-generated ROS release which in turn attenuated ROS-induced dysfunction of the cardiomyocyte sarcoplasmic reticulum. This putative effect would subsequently improve $\mathrm{Ca}^{2+}$ handling in the postreperfused cardiomyocyte, which would result in improved cardiac contractility [2]. As seen in previous studies, it should be emphasized that the cardioprotective effect of agents such as apocynin typically show a reduction in LVEDP, to ultimately manifest their improvement in cardiac function as represented by the increase in LVDP [17].

\subsubsection{Infarct Size}

Similar to the cardiac function data, the lowest dose tested $(5 \mu \mathrm{M})$ corresponded with the largest infarct size (30\%) among the Nox2ds-tat treated groups; however, this dose was still significantly different from $\mathrm{I} / \mathrm{R}$ control (46\%). However, this dose resulted in a significantly larger infarct size than the $10 \mu \mathrm{M}(\mathrm{p}<0.01)$ and $80 \mu \mathrm{M}(\mathrm{p}<0.05)$ doses. The $10 \mu \mathrm{M}, 40 \mu \mathrm{M}$, and $80 \mu \mathrm{M}$ doses all showed a significant reduction in infarct size $(15 \%-23 \%)$ when compared to control $(46 \%)$. We speculate that the improvement in LVDP is related to the attenuation of SO release in cardiac tissue seen with all three doses $(10 \mu \mathrm{M}, 40 \mu \mathrm{M}$, and $80 \mu \mathrm{M})$. This suggests that the degree of cell death is 
positively correlated with SO release from cardiac tissue and negatively correlated with restoration of post-reperfused cardiac function, findings which are consistent with our previous studies $[17,24,25]$.

\subsubsection{Leukocyte-Endothelial Interactions}

\subsubsection{Intravital Microscopy and H\&E Staining}

It is well known that SO can reduce NO bioavailability and form peroxynitrite anion [29]. Therefore, inhibiting Nox2 ROS generation would inhibit the quenching effect that SO exerts on NO bioavailability. This would in turn increase NO bioavailability which would reduce the upregulation of vascular adhesion molecules responsible for sequestering leukocytes to the vascular endothelium and initiating transmigration into tissue [3]. As expected, we observed a dose-dependent effect on leukocyte endothelial interactions in rat mesenteric venules. Similar to our ex vivo isolated heart model, the effect of the $5 \mu \mathrm{M}$ dose in this in vivo assay was not different from the L-NAME control, whereas the $20 \mu \mathrm{M}$ dose attenuated the L-NAME induced effect 3-5 fold (Table 2). This data suggests that L-NAME, via inhibiting NO production, induced an inflammatory response ultimately increasing Nox2 activity. Moreover, H\&E staining of mesenteric tissue isolated at the end of the intravital microscopy procedure corroborated the real-time data. More leukocytes were observed in mesenteric venules in the presence of L-NAME, an effect that was dose-dependently inhibited by Nox2ds-tat (Figure 7, Panel A-B). These findings are consistent with previous studies [24, 27].

\subsubsection{PMA-induced SO Release}

Only the $80 \mu \mathrm{M}$ dose showed a significant decrease in PMA-induced SO release from PMNs when compared to controls (Figure 3). We speculate the blunted effect of Nox2ds-tat $(10 \mu \mathrm{M}$ and $40 \mu \mathrm{M})$ on PMA-induced SO release from PMNs was due to restrictions within the membrane of neutrophils. First, research has shown the membrane cortex of neutrophils becomes rigid when exposed to mechanical stress during in vitro assays, making the surface resistant to deformation [30]. Moreover, this mechanical stress results in the reorganization and polymerization of a neutrophil's cytoskeleton, and the possible disruption of associated transporters and second messenger systems [31, 32]. Thus, in vitro cell transport mechanisms for TAT-internalization may not be equivalent to $e x$ vivo models which maintain a more intact transport system, perhaps due to less systematic stress upon the neutrophils. Second, hematopoietic stem cells such as PMNs are more resistant to TAT-internalization, especially when compared to cargo sequences conjugated with a smaller and more permeable cell penetrating peptide such as myristic acid [33, 34]. In final support of PMN resistance to TAT-conjugated peptide internalization, Rey et al. [19] found similar results in PMA-induced human PMN SO release when comparing the efficacy of Nox2dstat in a dose range similar to our own.

\subsubsection{Hindlimb I/R}

\subsubsection{Blood $\mathrm{H}_{2} \mathrm{O}_{2}$ release}

We chose to use $4.1 \mathrm{mg}$ of Nox2ds-tat per $\mathrm{kg}$ of tissue $(\sim 20 \mu \mathrm{M}$ in blood) because this was in the mid-dose range of the effective concentrations that showed a significant decrease in LVEDP (in our ex vivo cardiac function data). Compared to lose dose Nox 2 ds-tat $(5 \mu \mathrm{M})$, this dose reduced post-reperfused blood $\mathrm{H}_{2} \mathrm{O}_{2}$ levels back to sham control values by the end of the experiment (45 min reperfusion). By contrast, saline controls maintained post-reperfused $\mathrm{H}_{2} \mathrm{O}_{2}$ blood levels above sham control values throughout the reperfusion period (45 min). The data from this assay suggests Nox 2 activation and ROS production during reperfusion is the principal source of ROS in this I/R model, and mechanistically may explain the attenuation of infarct size observed in our isolated perfused heart model. This finding is consistent with our previous study [17]. Moreover, the hindlimb I/R assay further corroborates the speculation that Nox2 expressed in cardiovascular tissue is the principle source of ROS during reperfusion. 


\subsubsection{Blood NO release}

Nox2ds-tat completely reversed the effect of $\mathrm{I} / \mathrm{R}$ on $\mathrm{NO}$ bioavailability, which fell to $90 \mathrm{nM}$ below the sham limb in saline treated groups (Figure 6, Panel A). Administration of Nox2dstat maintained blood NO levels that did not significantly differ from the sham limb, however a total increase of $37 \mathrm{nM}$ above sham hindlimb values was observed (Figure 6, Panel B). Ultimately, the treatment significantly increased blood NO by $127 \mathrm{nM}$ above saline controls at the end of the reperfusion period (45 min) (Figure 6, Panel C). This effect was most likely the result of inhibiting Nox2-induced SO production and the subsequent attenuation of the quenching effect that ROS has on NO bioavailability [3]. This effect would also explain the decrease in leukocyte-endothelial interactions in mesenteric venules and the reduction of infarct size in the isolated perfused rat heart model.

\subsection{Role of Nox 2 in $I / R$ injury}

Nox 2 activation during reperfusion occurs as a result of proinflammatory cytokine receptor activation in leukocytes and cardiovascular tissue (e.g. TNF- $\alpha$ and NF- $\kappa \mathrm{B}$ ), accompanied by chemokine receptor upregulation and recruitment of inflammatory mediators. Since the majority of chemokine receptors integrate $\mathrm{G}$ protein coupled receptor kinases, this inflammation results in a cascade of events which culminate in PKC activation and a subsequent upregulation of Nox 2 $[12,13,35]$. Activation of Nox2 promotes endothelial dysfunction by diminishing the bioavailability of $\mathrm{NO}$ and propagating eNOS uncoupling via $\mathrm{BH}_{4}$ depletion; this will shift the product profile of eNOS to primarily producing SO instead of cardioprotective NO [29]. Moreover, Nox2 activation on organelle membranes will produce intracellular SO, which leads to uncoupling of the mitochondrial electron transport chain and additional ROS production [11]. The oxidation of xanthine dehydrogenase to xanthine oxidase will also favor the profile of this enzyme to produce SO $[1,2]$. Collectively, the activity of Nox 2 will lead to the induction of SO generation by the aforementioned sources and propagate the deleterious cycle of SO production and NO depletion characteristic of I/R injury.
The role that Nox2 plays in myocardial $\mathrm{I} / \mathrm{R}$ injury is crucial to understand since general antioxidants such as vitamin-C and vitamin-E have proven to be ineffective in the attenuation of SO injury in clinical myocardial $I / R$, in part because they have limited access in targeting the primary source generating this oxidative stress [1, 2]. Identifying a key source of ROS generation could be essential, since more than 50yrs have passed since reperfusion injury has been identified as a major clinical problem affecting MI patients, and there is still no pharmacological treatment to attenuate myocardial reperfusion injury [36]. I/R injury is a multifactorial process that is initiated by ROS generation, which in turn causes additional injury to adjacent cells and upregulation of inflammatory cytokines, which in turn attract more leukocytes to the area of injury, ultimately reinforcing a cascade of events that exacerbate the original ischemic injury. Attenuating the primary sources of oxidative stress during $\mathrm{I} / \mathrm{R}$ injury will inhibit downstream effects, such as histamine release from mast cells and TGF- $\beta$ secretion from injured cells; these events lead to the activation of NF- $\mathrm{KB}$ and programmed cell death, processes which occur on a chronic basis during the weeks following a MI [37]. Inhibiting the generation of ROS during $\mathrm{I} / \mathrm{R}$ injury in an early, effective, and selective manner will attenuate the downstream processes which result from SO release and more importantly minimize the chronic administration of pharmaceuticals aimed to mitigate the symptoms associated with cardiac remodeling following a MI.

\subsection{Future Studies}

Nox2ds-tat is a putative inhibitor of Nox2, the primary NADPH isoform in leukocytes and the cardiovascular system. NADPH oxidases are unique in their ability to perpetuate other sources of oxidative stress, lending to why this study focused specifically on this peptide. However, it would be of great interest to compare the effects of Nox2ds-tat alone versus the effects of this peptide in conjunction with inhibitors of the other three enzymatic sources of oxidative stress during $\mathrm{I} / \mathrm{R}$ injury (i.e. uncoupling of the mitochondrial electron transport chain, uncoupled eNOS, and 
xanthine oxidase formation). Our results for the 5 $\mu \mathrm{M}$ dose of Nox $2 \mathrm{ds}$-tat did not show significant recovery of post-reperfused cardiac function, but one may speculate that a low dose of Nox2ds-tat in conjunction with another selective peptide inhibitor of one of the other sources of $I / R$ induced ROS may render significant results. For example, SS-31, a targeted mitochondrial antioxidant peptide, has been shown to dosedependently improve post-reperfused LVDP and reduce infarct size in rat hearts subjected to I (30 $\mathrm{min}) / \mathrm{R}$ (45 $\mathrm{min}$ ), in a manner similar to Nox2dstat $[38,39]$. While a low dose of these peptides administered alone did not yield significant results, a combination of Nox 2 ds-tat $(5 \mu \mathrm{M})$ with SS-31 $(10 \mu \mathrm{M})$ synergistically improved postreperfused LVDP by $63 \pm 11 \%$ of initial values when compared to Nox2ds-tat $(5 \mu \mathrm{M})$ alone (Table 1), SS-31 alone $(10 \mu \mathrm{M})$, or control untreated I/R hearts that recovered to $47 \pm 7 \%$, $25 \pm 1 \%$, and $46 \pm 6 \%$ (Table 1 ), respectively [38]. These results are promising and lead to an important direction for future studies because they imply that lower doses of selective ROS inhibitory peptides may complement one another, and be used to synergistically reduce myocardial dysfunction during I/R injury. The use of lower doses can possibly minimize adverse drug reactions and immunological responses in target patient populations.

\section{References}

1. Yellon, D. M., \& Hausenloy, D. J. (2007). Myocardial reperfusion injury. New England Journal of Medicine, 357(11), 1121-1135. DOI: 10.1056/NEJMra071667

2. Hausenloy, D. J., \& Yellon, D. M. (2013). Myocardial ischemia-reperfusion injury: a neglected therapeutic target. Journal of Clinical Investigation, 123(1), 92-100. DOI: 10.1172/JCI62874

3. Lefer, A. M., \& Lefer, D. J. (1996). The role of nitric oxide and cell adhesion molecules on the microcirculation in ischaemiareperfusion. Cardiovascular Research, 32(4), 743-751. DOI: $10.1016 / 0008-$ $\underline{6363(96) 00073-9}$
4. Ago, T., Kuroda, J., Kamouchi, M., Sadoshima, J., \& Kitazono, T. (2011). Pathophysiological Roles of NADPH Oxidase/Nox family proteins in the vascular system-review and perspective. Circulation Journal, 75(8), 1791-1800. DOI: 10.1253/circj.CJ-11-0388

5. Doughan, A. K., Harrison, D. G., \& Dikalov, S. I. (2008). Molecular Mechanisms of Angiotensin II-Mediated Mitochondrial Dysfunction Linking Mitochondrial Oxidative Damage and Vascular Endothelial Dysfunction. Circulation research, 102(4), 488-496.

10.1161/CIRCRESAHA.107.162800

DOI:

6. Duda, M., Konior, A., Klemenska, E., \& Beręsewicz, A. (2007). Preconditioning protects endothelium by preventing ET-1induced activation of NADPH oxidase and xanthine oxidase in post-ischemic heart. Journal of Molecular and Cellular Cardiology, 42(2), 400-410. DOI: 10.1016/j.yjmcc.2006.10.014

7. Fabian, R. H., Perez-Polo, J. R., \& Kent, T. A. (2008). Perivascular nitric oxide and superoxide in neonatal cerebral hypoxiaischemia. American Journal of PhysiologyHeart and Circulatory Physiology, 295(4), H1809-H1814. DOI: 10.1152/ajpheart.00301.2007

8. Frangogiannis, N. G., Lindsey, M. L., Michael, L. H., Youker, K. A., Bressler, R. B., Mendoza, L. H., ... \& Entman, M. L. (1998). Resident cardiac mast cells degranulate and release preformed $\mathrm{TNF}-\alpha$, initiating the cytokine cascade in experimental canine myocardial ischemia/reperfusion. Circulation, 98(7), 699-710. DOI: 10.1161/01.CIR.98.7.699

9. Nolly, M. B., Caldiz, C. I., Yeves, A. M., Villa-Abrille, M. C., Morgan, P. E., Mondaca, N. A., ... \& Ennis, I. L. (2014). The signaling pathway for aldosteroneinduced mitochondrial production of superoxide anion in the myocardium. Journal of Molecular and Cellular Cardiology, 67, 60-68. DOI: $\underline{\text { 10.1016/j.yjmcc.2013.12.004 }}$ 
10. Kleniewska, P., Piechota, A., Skibska, B., \& Goraca, A. (2012). The NADPH oxidase family and its inhibitors. Archivum immunologiae et therapiae experimentalis, 60(4), 277-294. DOI: 10.1007/s00005-012$\underline{0176-\mathrm{Z}}$

11. Laurindo, F. R., Araujo, T. L., \& Abrahao, T. B. (2014). Nox NADPH oxidases and the endoplasmic reticulum. Antioxidants \& Redox Signaling, 20(17), 2755-2775. DOI: 10.1089/ars.2013.5605

12. Li, J. M., \& Shah, A. M. (2003). Mechanism of Endothelial Cell NADPH Oxidase Activation by Angiotensin II ROLE OF THE p47 phox SUBUNIT. Journal of Biological Chemistry, 278(14), 12094-12100. DOI: 10.1074/jbc.M209793200

13. Guggilam, A., Cardinale, J. P., Mariappan, N., Sriramula, S., Haque, M., \& Francis, J. (2011). Central TNF inhibition results in attenuated neurohumoral excitation in heart failure: a role for superoxide and nitric oxide. Basic Research in Cardiology, 106(2), 273286. DOI: $10.1007 / \mathrm{s} 00395-010-0146-8$

14. Xiao, H., Lu, M., Lin, T. Y., Chen, Z., Chen, G., Wang, W. C., ... \& Sun, W. (2013). SREBP2 activation of NLRP3 inflammasome in endothelium mediates hemodynamic-induced atherosclerosis susceptibility. Circulation, CIRCULATIONAHA-113. DOI: 10.1161/CIRCULATIONAHA.113.002714

15. Braunersreuther, V., Montecucco, F., Ashri, M., Pelli, G., Galan, K., Frias, M., ... \& Mach, F. (2013). Role of NADPH oxidase isoforms NOX1, NOX2 and NOX4 in myocardial ischemia/reperfusion injury. Journal of Molecular and Cellular Cardiology, 64, 99107. DOI: 10.1016/j.yjmcc.2013.09.007

16. Somasuntharam, I., Boopathy, A. V., Khan, R. S., Martinez, M. D., Brown, M. E., Murthy, N., \& Davis, M. E. (2013). Delivery of Nox2-NADPH oxidase siRNA with polyketal nanoparticles for improving cardiac function following myocardial infarction. Biomaterials, 34(31), 7790-7798. DOI: 10.1016/j.biomaterials.2013.06.051

17. Chen, Q., Parker, CW., Devine, I., Ondrasik, R., Habtamu, T., Bartol, K. D., Casey, B., ...
\& Young, L. (2016). Apocynin Exerts Dose-Dependent Cardioprotective Effects by Attenuating Reactive Oxygen Species in Ischemia/Reperfusion. Cardiovascular Pharmacology: Open Access, 2016. DOI: 10.4176/2329-6607.1000176

18. Johnson, D. K., Schillinger, K. J., Kwait, D. M., Hughes, C. V., McNamara, E. J., Ishmael, F., ... \& Santhanam, L. (2002). Inhibition of NADPH oxidase activation in endothelial cells by ortho-methoxy-substituted catechols. Endothelium, 9(3), 191-203. DOI: $\underline{10.1080 / 10623320213638}$

19. Rey, F. E., Cifuentes, M. E., Kiarash, A., Quinn, M. T., \& Pagano, P. J. (2001). Novel competitive inhibitor of $\mathrm{NAD}(\mathrm{P}) \mathrm{H}$ oxidase assembly attenuates vascular $\mathrm{O} 2-$ and systolic blood pressure in mice. Circulation Research, 89(5), 408-414. DOI: 10.1161/hh1701.096037

20. Csányi, G., Cifuentes-Pagano, E., Al Ghouleh, I., Ranayhossaini, D. J., Egaña, L., Lopes, L. R., ... \& Pagano, P. J. (2011). Nox2 B-loop peptide, Nox2ds, specifically inhibits the NADPH oxidase Nox2. Free Radical Biology and Medicine, 51(6), 11161125. DOI: 10.1016/j.freeradbiomed.2011.04.025

21. Cifuentes-Pagano, E., Meijles, D. N., \& Pagano, P. J. (2014). The quest for selective nox inhibitors and therapeutics: challenges, triumphs and pitfalls. Antioxidants \& Redox Signaling, 20(17), 2741-2754. DOI: 10.1089/ars.2013.5620

22. Jacobson, G. M., Dourron, H. M., Liu, J., Carretero, O. A., Reddy, D. J., Andrzejewski, T., \& Pagano, P. J. (2003). Novel NAD(P)H oxidase inhibitor suppresses angioplastyinduced superoxide and neointimal hyperplasia of rat carotid artery. Circulation Research, 92(6), 637-643. DOI: 10.1161/01.RES.0000063423.94645.8A

23. Perkins, K. A., Bartol, K., Chen, Q., Feinstein, E., \& Young, L. (2011). Myristoylation of protein kinase $\mathrm{C}$ beta II/zeta peptide inhibitors, or caveolin-1 peptide facilitates rapid attenuation of phorbol 12-myristate 13-acetate (PMA) or Nformyl-L-methionyl-L-leucyl-L- 
phenylalanine (fMLP) activated leukocyte superoxide release. Proceedings of the $22^{\text {nd }}$ American Peptide Symposium, Michal Lebl (Editor), American Peptide Society, 288-289.

24. Blakeman, N., Chen, Q., Tolson, J., Rueter, B., Diaz, B., Casey, B., ... \& Weis, M. T. (2012). Triacsin C, a fatty acyl coA synthetase inhibitor, improves cardiac performance following global ischemia. American Journal of Biomed Sciences, 4, 249-261. DOI: 10.5099/aj120300252

25. Chen, Q., Kim, E. E. J., Elio, K., Zambrano, C., Krass, S., Teng, J. C. W., ... \& Emrich, J. (2010). The role of tetrahydrobiopterin and dihydrobiopterin in ischemia/reperfusion injury when given at reperfusion. Advances in Pharmacological Sciences, vol. 2010, Article ID 963914. DOI: 10.1155/2010/963914

26. Young, L. H., Chen, Q., \& Weis, M. T. (2011). Direct Measurement of Hydrogen Peroxide $\left(\mathrm{H}_{2} \mathrm{O}_{2}\right)$ or Nitric Oxide (NO) Release: A Powerful Tool to Assess Realtime Free Radical Production in Biological Models. American Journal of Biomed Sciences, 3(1), 40-48. $\quad$ DOI: 10.5099/aj110100040

27. Chen, Q., Rueter, B., Krass, S., Zambrano, C., Thomas, S., Prince, C., ... \& Young, L. (2010). The potential clinical application of protein kinase $\mathrm{C}$ beta II peptide inhibitor or Gö 6983 in vascular endothelial dysfunction. Current Topics in Pharmacology, 14(4), 1124

http://www.researchtrends.net/tia/abstract.as $\mathrm{p}$ ?in $=0 \& v n=14 \& \mathrm{tid}=11 \&$ aid $=3050 \& \mathrm{pub}=20$ 10\&type $=3$

28. Young, L. H., Balin, B. J., \& Weis, M. T. (2005). Go 6983: a fast acting protein kinase $\mathrm{C}$ inhibitor that attenuates myocardial ischemia/reperfusion injury. Cardiovascular Drug Reviews, 23(3), 255-272. DOI: 10.1111/j.1527-3466.2005.tb00170.x

29. Schmidt, T. S., \& Alp, N. J. (2007). Mechanisms for the role of tetrahydrobiopterin in endothelial function and vascular disease. Clinical Science, 113(2), 47-63. DOI: 10.1042/CS20070108
30. Zhelev, D. V., Needham, D., \& Hochmuth, R. M. (1994). Role of the membrane cortex in neutrophil deformation in small pipets. Biophysical Journal, 67(2), 696-705. DOI: 10.1016/S0006-3495(94)80529-6

31. Zhelev, D. V., \& Hochmuth, R. M. (1995). Mechanically stimulated cytoskeleton rearrangement and cortical contraction in human neutrophils. Biophysical Journal, 68(5), 2004-2014. DOI: 10.1016/S00063495(95)80377-2

32. Mills, J. W., \& Mandel, L. J. (1994). Cytoskeletal regulation of membrane transport events. The FASEB Journal, 8(14), 1161-1165.

33. Manceur, A., Wu, A., \& Audet, J. (2007). Flow cytometric screening of cellpenetrating peptides for their uptake into embryonic and adult stem cells. Analytical Biochemistry, 364(1), 51-59. DOI: 10.1016/j.ab.2007.02.015

34. Nelson, A. R., Borland, L., Allbritton, N. L., \& Sims, C. E. (2007). Myristoyl-based transport of peptides into living cells. Biochemistry, 46(51), 14771-14781. DOI: 10.1021/bi701295k

35. Soriano, S. F., Serrano, A., Hernanz - Falcón, P., de Ana, A. M., Monterrubio, M., Martínez - A, C., ... \& Mellado, M. (2003). Chemokines integrate JAK/STAT and G protein pathways during chemotaxis and calcium flux responses. European Journal of Immunology, 33(5), 1328-1333. DOI: 10.1002/eji.200323897

36. Jennings, R. Á., Sommers, H. Á., Smyth, G. A., Flack, H. A., \& Linn, H. (1960). Myocardial necrosis induced by temporary occlusion of a coronary artery in the dog. Archives of Pathology, 70, 68-78.

37. Palaniyandi, S. S., Ferreira, J. C. B., Brum, P. C., \& Mochly - Rosen, D. (2011). PKC $\beta I I$ inhibition attenuates myocardial infarction induced heart failure and is associated with a reduction of fibrosis and pro - inflammatory responses. Journal of Cellular and Molecular Medicine, 15(8), 1769-1777. DOI: $\underline{10.1111 / \mathrm{j} .1582-4934.2010 .01174 . \mathrm{x}}$ 
38. Patel, H., Walker, S., Chau, W., Devine, I., Ondrasik, R., Chen, Q., ... \& Young, L. (2014). Combinational effects of gp91 ds-tat and SS-31 in reducing myocardial/ischemia reperfusion injury. The FASEB Journal, 28(1 Supplement), 1080-8.

39. Ondrasik, R., Chen, Q., Navitsky, K., Chau, W., Lau, O. S., Devine, I., ... \& Young, L. H. (2013). Cardioprotective Effects of Selective Mitochondrial-Targeted Antioxidants in
Myocardial Ischemia/Reperfusion (I/R) Injury. Proceedings of the 23rd American Peptide Symposium, Michal Lebl (Editor). American Peptide Society, 64-65. DOI: 10.17952/23APS.2013.064

40. Wilkinson, B. L., \& Landreth, G. E. (2006). The microglial NADPH oxidase complex as a source of oxidative stress in Alzheimer's disease. Journal of Neuroinflammation, 3(1), 1. DOI: $10.1186 / 1742-2094-3-30$ 